\title{
A economia do care*
}

\author{
The economy of care
}

Viviana Zelizer**

Resumo: Durante os últimos decênios, tanto nos Estados Unidos quanto na Europa, a sociologia econômica passou, da atenção exclusiva às firmas, aos mercados e à sua teorização pela ciência econômica, a abordagens mais amplas e criativas das relações interpessoais e da atividade econômica em um grande número de domínios. O estudo do care, gratuito ou remunerado, ilustra bem estas novas tendências.

Palavras-chave: Care; Compensação; Imigração; Sociologia econômica; Cuidados pessoais

Abstract: In recent decades, in both Europe and USA, economic sociology has moved away from strict concentration on individual firms, markets, and their representations in economic theory toward more generous and creative treatments of interpersonal relations and of economic activity in a wide variety of settings. The study of interpersonal care, both paid and unpaid, illustrates these trends.

Keywords: Care, Compensation, Immigration, Economic sociology, Personal caring

Durante os últimos vinte e cinco anos, a sociologia econômica viveu mudanças consideráveis. Tendo partindo de uma posição simultaneamente crítica e complementar à economia neoclássica, ela é hoje uma disciplina

\footnotetext{
* O artigo "L'économie du care" foi publicado originalmente na Revue Française de Sócioéconomie, 2008, n. 2, p. 13-25. A tradução e a publicação desse texto foram autorizadas pela autora e pela editora La Decouverte, detentora dos direitos de publicação para todos os países <www. editionsladecouverte.fr>. Tradução para o português: Maria A. Müller e Lúcia Helena A. Müller. Utilizei algumas passagens da obra Purchase of intimacy (Princeton University Press, 2005) e de "Pasts and Futures of Economic Sociology" (American Behavioral Scientist, 2007, 50(8), p. 1056-1069). Este artigo é uma adaptação de uma comunicação apresentada no colóquio sobre a sociologia econômica do care, no Centre de Recherche Interdisciplinaire pour la Sociologie Économique (LISE, CNRS), Paris, 8 de junho de 2006.

**Doutora em sociologia pela Universidade de Columbia, professora da Universidade de Princeton, EUA. Autora dos livros: Moral and markets: the development of life insurande in the United States (1979); Princing the pricelless child: the changing social value of children (1985); The social meaning of money (1994); The purchase of intimacy (2005). <vzelizer@princeton.edu>.
}

\begin{tabular}{|l|l|l|l|l|l|}
\hline Civitas & Porto Alegre & v. 10 & n. 3 & p. 376-391 & set.-dez. 2010 \\
\hline
\end{tabular}


rica e autônoma, que começou a produzir ou a incorporar alternativas reais à economia neoclássica. Estas mudanças modificaram profundamente minha própria atitude em relação à sociologia econômica e minha relação com ela. A história desta relação é bastante curiosa. Durante muito tempo eu trabalhei sobre diversos processos econômicos, escrevi livros sobre a invenção do seguro de vida, sobre a "avaliação" do valor econômico das crianças, sobre as práticas monetárias interpessoais e, mais recentemente, sobre a economia das relações sociais íntimas. Fiz incursões mais breves sobre assuntos que indiscutivelmente fazem parte do domínio da economia, como o consumo e o trabalho das crianças. No entanto, durante anos, ninguém, nem eu mesma, chamei o que eu fazia de "sociologia econômica".

Seguiremos neste artigo a evolução desta disciplina, estudando particularmente a maneira como ela aborda a análise da economia do care. Durante muitos anos, os sociólogos da economia ignoraram o care e o fato deste tema ter se tornado um objeto de estudo para a sociologia econômica é revelador da transformação desse campo.

A sociologia econômica, que ganhou amplitude há 20 ou 25 anos nos Estados Unidos, era, no início, muito próxima da economia neoclássica. Para ela, tratava-se de transpor os conceitos desta última a assuntos habitualmente relevantes para a sociologia ou de colocar em evidência contextos sociais que atrapalhavam a atividade econômica que, continuava-se a supor, desenvolviase segundo os preceitos da economia neoclássica. Tratava-se, então, quase que exclusivamente de empresas e de mercados, assuntos favoritos dos economistas. A ênfase era colocada, portanto, sobre o que se pode chamar de ponto de vista da "extensão" e de ponto de vista do "contexto".

Os teóricos da "extensão" aplicavam modelos econômicos relativamente standard a processos aparentemente não econômicos, como as congregações religiosas, o comportamento das famílias ou as equipes de esporte profissional. As análises do "contexto" se interessavam por fenômenos econômicos standard, como os mercados de trabalho, os mercados de commodities ou as empresas, mostrando como a organização social, como contexto, formatava as opções dos atores econômicos. Os advogados do "contexto" falavam de imersão ${ }^{1}$ do fenômeno econômico em processos sociais, e faziam referências

\footnotetext{
1 Notas das tradutoras: Ao traduzir para o português o termo encastrement (incrustado, embutido) tomamos como referência a tradução para o português do texto de Mark Granovetter (1985), Economic action and social structure: the problem of embeddedness, em que o conceito embeddedness foi traduzido por "imersão" (Ver GRANOVETTER, Mark. Ação econômica e estrutura social: o problema da imersão. RAE-eletrônica, v. 6, n. 1, art. 5, jan./jun. 2007. Também publicado em MARTES, Ana Cristina (Org.). Redes e sociologia econômica, São Paulo, EdUFSCar, 2009).
} 
frequentes a redes interpessoais. Segundo eles, a teoria econômica era válida quando se tratava de explicar fenômenos tais como as negociações ou a fixação dos preços. A seus olhos, os economistas tinham simplesmente negligenciado a importância do contexto cultural e social como, por exemplo, as relações pré-existentes entre parceiros econômicos potenciais.

No curso dos últimos 10 ou 15 anos, fiquei surpresa ao ver que eu havia me tornado membro do Who's Who da sociologia econômica. O que se passou nesse meio tempo? Em parte, é porque eu tinha aprendido mais sobre a diversidade dos trabalhos realizados em sociologia econômica, e tido uma participação maior num debate cada vez mais vivo. Três mudanças na minha relação com a disciplina foram muito importantes:

1. primeiro, os animadores intelectuais da sociologia econômica nos Estados Unidos, como Richard Swedberg, Harrison White e Neil Smelser, começaram a citar meus trabalhos como exemplos de uma nova corrente no interior da disciplina;

2. a seguir, me pus a ensinar "sociologia econômica" a grupos cada vez mais repletos de estudantes, tanto de primeiro como de segundo ciclo;

3. por fim, as duas primeiras mudanças fizeram com que eu me confrontasse com os grandes princípios que fundamentam a sociologia econômica de forma mais direta do que quando eu me considerava, antes de mais nada, uma especialista em história e cultura americanas.

Ao invés de só se interessar por empresas e por mercados, parecia-me que os especialistas em sociologia econômica, inclusive eu, deviam interessarse por todas as formas de produção, consumo, distribuição e transferência de capitais. Esta decisão de abrir o campo da sociologia econômica coloca, entretanto, um dilema. Como criar uma sociologia econômica na qual o trabalho fora do mercado, o care, portanto, ocupe um lugar pleno, coerente, mantendo, ao mesmo tempo, conexões com todas as atividades econômicas, não importa o contexto, inclusive o das empresas? Pelo menos nos Estados Unidos, esta integração ainda não aconteceu.

A sociologia econômica não é a única a desafiar os enfoques standard dos processos econômicos. Enquanto mudanças importantes se produziam na sociologia econômica, mudanças similares aconteciam em outros lugares. Dentre elas, três merecem uma atenção especial.

Primeiramente, no seio da própria economia, correntes como a economia comportamental, a economia feminista, a economia organizacional, a economia institucional, a dinâmica das famílias e, mais recentemente, a neuroeconomia, produziram suas próprias críticas aos modelos neoclássicos. Por exemplo, os próprios economistas criticam a noção de "comportamento doméstico", 
reduzida à decisão de um único agente. Todas estas novas formas de economia começaram a propor visões alternativas dos processos econômicos, entre as quais, a gama de relações interpessoais pelas quais eu me interessei durante muitos anos. Algo tão simples como a introdução da teoria dos jogos no modelo de negociação das famílias, por exemplo, fez com que um conjunto de interações entre jogadores substituísse as escolhas preferenciais únicas dos modelos anteriores.

Em segundo lugar, fora da economia, os especialistas do campo do "direito e economia", os teóricos das organizações, os especialistas das desigualdades e os teóricos do feminismo, contribuíram para o conhecimento do funcionamento real dos processos econômicos e sociais. Eles também deram ênfase ao poder, à negociação e às transações interpessoais.

Em terceiro lugar, nas fronteiras entre a economia e a sociologia, emergiram muitas novas disciplinas híbridas que propuseram novas versões dos processos econômicos, entre as quais, a "sócio-economia", a "economia comunitária" e a análise dos sistemas mundiais, bem como a "economia social e solidária" francesa.

Ao mesmo tempo, os especialistas em sociologia econômica viram seu número e sua confiança crescerem, e também se afastaram cada vez mais do ponto de vista da "extensão" e do "contexto". Pouco a pouco, eles formularam uma descrição e uma explicação sociais da atividade econômica que concorrem verdadeiramente com a da economia standard. Um poderoso movimento paralelo produziu-se nas ciências sociais francesas. ${ }^{2}$ Recusando qualquer divisão intrínseca entre a sociologia e a economia, André Orléan (2005), por exemplo, lançou recentemente um vibrante apelo em prol do que eu identifico como visões alternativas da atividade econômica em geral.

Esta análise alternativa tenta identificar os processos e as relações sociais no próprio coração da atividade econômica, incluindo, aí, o território sagrado e até o presente inexplorado dos próprios mercados. Muitas destas análises estão ligadas à declaração de Harrisom White, segundo a qual os mercados são criações profundamente sociais e não arenas autônomas as quais os processos sociais não fazem mais do que invadir.

Da mesma forma que os economistas institucionais que, impressionados pela incapacidade dos mercados transformarem, por si só, as economias pós-

2 Consultar, por exemplo, L'Argent en famille, 2005, assim como Boltanki e Chiapello, 1999; Caillé, 1944; Callon, 1998; Convert e Heilbron, 2004, Cousin e Benamouzig, 2004; De La Pradelle, 1996; Dufy e Weber, 2007; Gislain e Steiner, 1995; Guérin, 2003; Hassoun, 2005; Lebaron, 2000; This Saint-Jean e Steiner, 2005; Sciardet, 2003; Servet, 1999; Servet e Guérin, 2002; Steiner, 1999, 2003; Weber, Gojard e Gramain, 2003; Weber, 2005; Wacquant, 2002. 
socialistas, começaram a representar as atividades econômicas como processos sociais, os sociólogos economistas aventuraram-se no próprio coração das empresas, dos mercados, das organizações e das instituições financeiras.

No decorrer de seus últimos anos, Pierre Bourdieu seguia na mesma direção. Em Strutures sociales de l'economie, ele declarou:

As estratégias que visam "corrigir" as insuficiências ou as lacunas de um paradigma sem jamais o colocarem verdadeiramente em questão, Herbert Simon falando de "racionalidade limitada" ou Marc Granovetter reintroduzindo as social networks, nos fazem pensar nas laboriosas construções através das quais Tycho-Brahé se esforçava para salvar o modelo geocêntrico de Ptolomeu contra a revolução copernicana (Bourdieu, 2000, p. 12, nota 1).

Em geral, os sociólogos que buscam uma sociologia econômica alternativa criticam a idéia de imersão que, segundo eles, implica que os processos sociais forneçam apenas o "recipiente" da economia, enquanto que o conteúdo permaneceria identificado por sistemas racionais de troca da economia standard. É o que diz claramente Isabelle This Saint-Jean, em um número recente do L'Année sociologique:

Efetivamente, quando os autores afirmam que os "fatos econômicos" estão "imersos" no social, no "político", no "cultural" ou no "cognitivo", eles supõem, ao mesmo tempo, a existência de algo que pode ser identificado como "econômico" e diferenciada do "social", do "político", do "cultural" e do "cognitivo"... De certa maneira, então, eles próprios desenham precisamente a fronteira que procuram colocar em questão [This Saint-Jean, 2005].

\section{Os cuidados e o care}

O estudo do personal care como atividade econômica ilustra perfeitamente a evolução que acabo de descrever. O que se deve entender por care? Para mim, as relações de care incluem qualquer tipo de atenção pessoal, constante e/ou intensa, que visa melhorar o bem estar daquela ou daquele que é seu objeto. Assim, pode-se definir um leque de "atenções pessoais constantes e/ ou intensas" que tem, numa extremidade, o cuidado da manicure num salão de beleza ou o breve conselho telefônico num hotline de ajuda psicológica, e, na outra, os laços estabelecidos ao longo de uma vida inteira entre uma mãe e sua filha, ou, ainda, o devotamento de um velho empregado.

Os especialistas do care produziram um grande número de trabalhos de pesquisa, mas estes trabalhos ficaram essencialmente à margem da sociologia econômica propriamente dita. Os especialistas do care são críticos da visão 
econômica, mas eles ainda não contribuem verdadeiramente para a análise econômica em si mesma.

Eu começaria evocando um processo judiciário dramático que ilustra bem o problema analítico para, em seguida, explorar certas formas de resolvê-lo.

Este processo diz respeito a um conflito, de 1980, relativo ao pagamento de uma cuidadora de crianças. Naquele ano, a corte do Distrito de Columbia julgou o muito contestado caso Lopez contra Rodriguez. ${ }^{3}$ Tudo havia começado quatro anos antes, quando Manuel e Mirtha Rodriguez, imigrantes bolivianos, residentes na região de Washington D. C., foram visitar seu domicílio anterior, em Cochabamba, Bolívia. Naquela ocasião, em Cochabamba, Gabina Camacho Lopez cuidou dos três filhos dos Rodriguez, no domicílio de sua avó, a mãe do Sr. Rodriguez. No fim de sua visita, os Rodriguez levaram Gabina e as crianças para Washington, junto com eles.

Como imigrante ilegal, conhecendo mal o inglês, Gabina viu-se sequestrada no domicílio dos Rodriguez. Durante cerca de três anos, cozinhou, limpou e tomou conta das crianças Rodriguez. Durante estes anos, Gabina jamais saiu sozinha do domicílio dos Rodriguez. Como compensação, os Rodriguez lhe forneceram habitação e refeições, "diversas roupas e artigos de toalete, despesas médicas e uma pequena mesada". Eles disseram a Gabina que depositavam seu salário no banco. Em 1979, depois que os Rodriguez se recusaram a dar o dinheiro que Gabina lhes pedia, e como eles também a impediam de fazer amigos e ir à igreja, Gabina recorreu à justiça. Ela reclamou os salários devidos e não pagos nos termos do "Fair Labor Standards Act".

É claro que o caso Lopez levanta questões de justiça e de exploração. Mas a questão primordial, neste caso, foi a de saber se Gabina preenchia as condições requeridas para ser considerada empregada nos termos do "Fair Labor Standards Act”. Os Rodriguez se recusaram a considerá-la como sua empregada. Os advogados de Lopez insistiram, porém, no fato dela ser justamente uma empregada mal remunerada, explorada. Eles evidenciaram que, na declaração de renda de 1976, os Rodriguez tinham solicitado um desconto relativo ao cuidado das crianças de US\$ 900, para os serviços de Gabina.

Finalmente, os vários tribunais implicados concederam a Gabina um salário mínimo de US\$28.000 e o mesmo montante por danos, incluindo custas judiciais e descontado o montante que os Rodriguez tinham realmente gasto com o quarto e a pensão.

3 Lopez v. Rodriguez; 500 F. Supp. 79; 1980 U.S. Dist. LEXIS 14841; 215 U.S. App. D.C. 344; 668 F. 2d. 1376; 1981 U.S. App. LEXIS 15854. 
Desse litígio, destacam-se dois pontos. Antes de mais nada, ninguém se recusou a admitir que Lopez tenha prestado o care para os Rodriguez e seus filhos, ou mesmo que ela tenha recebido uma pequena compensação monetária por este care. A questão era: qual a sua relação com a família Rodriguez na situação em que o care era fornecido? Em segundo lugar, o tribunal fez uma escolha essencialmente dicotômica: Gabina Lopez era ou uma amiga ajudando a família Rodriguez, fazendo seu trabalho gratuitamente e recebendo a consideração habitual devida a um membro da família, ou uma empregada do setor de serviços comerciais e, por consequência, sujeita às leis que regem os salários e as relações entre empregador e empregado. Os tribunais aceitaram os argumentos dos advogados de Lopez, segundo os quais as relações entre Gabina e os Rodriguez faziam parte da segunda categoria. Gabina e seus advogados venceram.

O caso Lopez representa apenas uma versão do conjunto de questões legais, morais, analíticas e de ordem política que necessitam de uma resposta rápida:

Primeiramente, quais são as diferentes definições que concorrem entre si acerca da relação entre os provedores de care e as famílias para as quais eles trabalham?

Em segundo lugar, quais as obrigações mútuas que decorrem da definição adotada pelas partes?

Em terceiro lugar, sobre quais pontos da relação dão-se regularmente os litígios e as confusões?

Em quarto lugar, até que ponto, e como, a introdução de acertos monetários nestas relações afeta a sua natureza?

Em quinto lugar, enquanto analistas, como podemos explicar o conflito e a confusão que emergem tão frequentemente das relações entre provedores de care e as famílias para as quais eles trabalham, sobretudo quando se trata de dinheiro e quando as crianças estão envolvidas?

Voltaremos (cfr. Infra) a estes problemas de maneira mais geral.

O problema da compensação do care vai, é claro, muito além do cuidado das crianças, como no caso Lopez, e engloba de forma geral todos os trabalhos de care. O care pago deve, portanto, enfrentar as mesmas dificuldades e problemas que aparecem a cada vez que se tenta pensar nas relações entre a atividade mercantil e as obrigações sociais. Muitos se perguntam o que aconteceria se o care pago substituísse a ajuda informal. Sua submissão aos cálculos monetários eliminaria de maneira racional sua intimidade essencial? O cuidado de crianças pago é geral e necessariamente inferior ao cuidado feito por pessoas próximas? Que tipo de pagamento torna um care "superior"? 
Em todo caso, como podemos fazer uma avaliação financeira apropriada das contribuições dos provedores de care?

Pode-se distinguir três maneiras muito distintas de pensar estes problemas. Podemos chamá-las de Mundos hostis, Comércio em toda parte e Relações bem ajustadas. De acordo com Mundos hostis, quando se mistura com o care, o dinheiro só pode criar problemas; é preciso, então, separá-los tanto quanto possível, sobretudo quando o care acontece no seio das famílias. De acordo com Comércio em toda parte, ao contrário, basta olhar mais de perto para se ver que as relações de care são pura e simplesmente formas especiais de relações comerciais e que o problema é, antes de mais nada, o de definir o preço justo. A um e outro, Relações bem ajustadas responde que há uma interação permanente entre o care e as considerações econômicas, e que o conjunto só funciona quando os dois estão bem afinados. Por "bem ajustadas" não quero dizer que você ou eu aprovaríamos a negociação ou que o acerto seja adequado e justo. Quero dizer que o ajuste é viável: o aspecto econômico da relação é aceito e assegura a sua continuidade.

Há quatro características essenciais nas Relações bem ajustadas:

1. as transações econômicas distinguem a relação de outras relações com as quais poderíamos confundi-la e, assim, estragar a própria relação, por exemplo, confusão entre as doações monetárias feitas a uma irmã que participa do cuidado dos filhos e o salário de um cuidador de crianças profissional.

2. as Relações bem ajustadas são como uma demonstração e uma promulgação dos acordos entre os parceiros da relação: eles partilham uma visão comum do que é esta relação como, por exemplo, uma visão partilhada pelos pais e pela baby-sitter, relativa ao trabalho que a baby-sitter deve prestar em troca do pagamento que recebe por hora.

3. as Relações bem ajustadas reforçam os aspectos da relação que beneficiam as partes e asseguram a continuidade da própria relação, por exemplo, no caso de relações a longo prazo, através de contribuições financeiras em prol do bem-estar econômico futuro da cuidadora, que favorecem seu engajamento e confiança a longo prazo.

4. finalmente, as Relações bem ajustadas identificam claramente a relação frente a terceiros que possam ser afetados, por exemplo, o que significa aos olhos de seus irmãos e irmãs que não são remunerados o pagamento que é feito a um filho em troca de seus serviços.

Para explorar a importância e a sutileza das Relações bem ajustadas nas relações de care, tomemos o exemplo das nannies (babás). Nanny, assim 
como o termo mais austero governess (governante), é uma palavra britânica que designa uma mulher - quase sempre uma mulher - que vive em uma família e assume como responsabilidade principal o cuidado das crianças. As questões evocadas anteriormente se colocam novamente de maneira ainda mais premente no caso das babás. Qual a relação entre este provedor de care, a criança, os adultos e a família em seu conjunto? Trata-se de um assalariado cujas compensações são pouco elevadas mas a quem é fornecida habitação e alimentação, como se fizessem parte de seu salário; ou ela é um membro da família que, como os outros membros, tem responsabilidades especiais em relação à atividade econômica familiar? Ou não é nada disso?

Percebemos que muitos respondem a estas questões com certezas do tipo Mundos hostis; para eles, as babás devem, antes de tudo, ter perfeitas relações de afeto com as crianças e com as famílias para as quais trabalham, e colocar em surdina tanto quanto possível as considerações econômicas. Em seu livro de sucesso, The Nanny Diaries, Emma McLaughin e Nicola Kraus mostram como o ponto de vista dos Mundos hostis formata o trabalho, como ilustra esta primeira conversação:

O que se aproxima mais da possibilidade de que eu poderia verdadeiramente fazer por dinheiro é o tema da minha experiência de baby-sitter, que eu descrevo como um hobby apaixonante, como o seria a criação de cães para cegos. Ao longo da conversação, eu me tornei uma expert em matéria de desenvolvimento de crianças nós dois nos convencemos do meu desejo de satisfazer minha alma criando uma criança (Mc Laughin e Kraus, 2002, p. 3).

Reagindo à retórica do tipo Mundos hostis, os partidários do realismo replicam com o modelo Comércio em toda parte: segundo eles, o cuidado de crianças não é diferente de qualquer outra transação econômica. O trabalho de care funciona segundo os mesmos princípios que os das transferências de ações ou da venda de carros em liquidação, e o mundo ostensivamente separado do care não é mais do que um caso particular de racionalidade econômica.

Entretanto, se olharmos de perto a vida de trabalho das babás, constatamos rapidamente que suas relações com as crianças e os pais não se assemelham a simples relações de amor nem a transações comerciais comuns. A negociação em torno da adequação entre o trabalho, as relações interpessoais e as formas de compensação preocupam estas empregadas, têm um grande impacto sobre o care que elas oferecem, e determinam se elas conservam ou perdem o seu trabalho.

O estudo de Pierrette Hondagneu-Sotelo sobre empregadas domésticas imigradas da América Latina para Los Angeles mostra como as mulheres e 
as famílias para as quais elas trabalhavam negociaram acordos complexos e muitas vezes tensos sobre questões como o número de horas de trabalho, os tipos de folgas autorizados, o valor da remuneração, a possibilidade ou não delas se servirem da comida da família, o lugar onde elas dormirão e, de forma mais geral, sobre a relação com os outros membros da família.

É evidente que as partes engajadas nestes contratos de trabalho exercem um poder muito desigual. Segundo os resultados estabelecidos por Sotelo, os contratantes de empregadas domésticas alojadas geralmente decidem os salários consultando seus próprios amigos. Candance Ross, por exemplo, conta como decidiu o salário de sua primeira empregada contratada:

Eu perguntei [o que os vizinhos pagavam] e, hum, eu encontrei uma verdadeira faixa de preços que ia de 125 \$ por semana, até cerca de $200 \$$, é porque que nós a havíamos contratado por $150 \$$, o que, a meu ver, era, um bom acerto (Hondagneu-Sotelo, 2001, p. 82).

Os pais que pagam mais dizem sentir uma pressão da parte de seus vizinhos para que abaixem os salários. Ao mesmo tempo em que utilizam suas próprias redes para definirem o preço praticado, geralmente os empregadores tentam impedir que suas empregadas consultem suas colegas que trabalham na casa dos vizinhos. Sotelo encontrou até mesmo empregadores que proíbem suas empregadas de levarem seus filhos ao parque, temendo que as outras façam alusão a salários mais elevados e a oportunidades mais interessantes.

Negociações muito desiguais quanto aos detalhes do trabalho de empregada doméstica resultam recorrentemente no que Sotelo chama de blowups: "empregos que acabam numa bela briga". Porém, como é de se esperar, certas empregadas e seus empregadores desenvolvem relações econômicas mais equilibradas. Em suas entrevistas com pais de classe média superior e suas empregadas, em Los Angeles e Nova Iorque, Julia Wrigley ouviu de empregadores que eles fornecem uma variedade de serviços a suas empregadas: empréstimo de dinheiro, pagamento de contas médicas e odontológicas, encaminhamento a seus próprios médicos, ajuda para negociar com proprietários ou credores ou mesmo para tirar um parente da empregada da prisão.

Os especialistas franceses do care identificaram problemas paralelos nas relações entre as empregadas domésticas e seus empregadores. Liliane Bernardo, por exemplo, põe em evidência a coexistência, nestas relações, de laços íntimos com laços de empregador com empregada: "Ela é mais que uma simples empregada doméstica", diz um empregador, "Eu me sinto em minha casa, aqui. Os filhos de Mme. Dubois são meus filhos também" conta uma empregada. Bernardo fala de "duplo registro", às vezes, suas entrevistadas 
declaram francamente: "Eu sou empregada doméstica e, ao mesmo tempo, não sou empregada doméstica" ou "há a Régine amiga e a Régine empregada doméstica" (Bernardo, 2003, p. 363).

As transações econômicas entre empregador e empregada refletem esta relação dual: a mesma tarefa, por exemplo, buscar uma criança na escola, poderia ser definida como fazendo parte do trabalho previsto para a empregada em troca de seu salário, ou como um favor feito ao empregador e, portanto, como uma prestação, em uma lógica de troca de dons. Como explica um empregador:

São serviços que ela me presta, neste caso. E é Régine que os presta a mim, porque ela ama nos servir, mas não é como empregada doméstica que ela nos serve, mas enquanto amiga... Nós não a pagamos, mas lhe damos presentes nestes casos. Não lhe daremos 100 francos, mas uma caixa de chocolate ou flores... Se eu a pagasse, a humilharia. De todo modo, ela não aceitaria dinheiro (Bernardo, 2003, p. 369).

Este tipo de empregador hesita, portanto, entre Mundos hostis e Comércio em toda parte, sem realizar a possibilidade de Relações bem ajustadas. As Relações bem ajustadas não garantem que tudo vá bem quando as babás são tratadas generosamente. Ao contrário, a relação entre as babás e seus empregadores é tão complexa quanto as relações entre esposos, filhos, parentes ou amigos: os maus arranjos e as transações econômicas que por elas transitam trazem prejuízo às relações, enquanto que bons arranjos facilitam as relações e se traduzem em uma colaboração mais eficaz.

\section{Para uma nova economia do care}

Quais são as implicações práticas de tal enfoque? Trata-se de se observar qual o conjunto de transações econômicas que parecem justas e não coercitivas, para os diferentes tipos de relações de care. O objetivo não é, então, o de eliminar a intimidade das questões econômicas: o problema é criar combinações equitativas. Não se trata de se perguntar se o dinheiro corrompe ou não, mas, sobretudo, de analisar as combinações entre as atividades econômicas e as relações de care que dão lugar a situações mais felizes, mais justas e mais produtivas. Não é a combinação em si mesma que deve nos interessar, mas o modo como ela funciona. Se identificarmos mal as conexões causais, ocultaremos a origem das injustiças, dos danos e dos perigos.

Naturalmente, outros especialistas do care propõem conclusões semelhantes a nossa. Um grupo de pensadores feministas imaginativos, cada vez mais crítico das respostas standar do tipo Mundo hostil e Comércio em 
toda parte, desenvolveu um enfoque alternativo bem no espírito das Relações bem ajustadas. Eles identificam muitas formas de conexão entre as relações íntimas e as diferentes esferas da vida econômica. Questionando a idealização do care não remunerado, estes analistas avaliam as possibilidades e exploram as práticas atuais em que remuneração e care coexistem de modo frutífero. Neste caso, eles constroem uma nova economia do care.

Assim é que os economistas Nancy Folbre e Julie Nelson afirmam:

O julgamento a priori de que os mercados devem melhorar a atividade de care aumentando a sua eficácia é mais um freio do que um encorajamento à pesquisa inteligente sobre o tema.

Ao inverso, o julgamento a priori segundo o qual os mercados não podem senão degradar seriamente as atividades do care ao substituir as motivações altruístas por interesses pessoais constitui da mesma forma um freio à pesquisa. Em vez disso, eles afirmam: "a imbricação cada vez mais frequente do "amor" e do "dinheiro" nos mostra a necessidade - e a oportunidade - do engajamento em pesquisas e ações inovadoras" (Folbre e Nelson, 2000, p. 123-124).

Enfatizando o caráter social e relacional do cuidado de crianças, Julie Nelson chama igualmente a atenção para o fato dos pais e das "enfermeiras" raramente definirem este mercado "como uma troca puramente impessoal de dinheiro por serviços (...) as partes envolvidas se engajam em contatos pessoais extensivos, relações de confiança, interações interpessoais". Segundo ela, "o espetro do mercado corruptor impede de vermos que as pessoas - à imagem de muitas cuidadoras de crianças - possam fazer o trabalho que amam, estando entre aqueles que amam, sendo, ao mesmo tempo, remuneradas" (Nelson, 1998, p. 1470). Nelson insiste na idéia de que "o care pago não deve ser tratado como secundário do ponto de vista relacional, de uma qualidade relacional degradada" (ibid).

Mais recentemente, na nova edição do Handbook of Economic Sociology de Nell Smelser e Richard Swedberg, Paula England e Nancy Folbre criticam a economia neoclássica, bem como a sociologia econômica, por sua tendência "a recusar o estudo - justamente como 'não econômico' - dos domínios da atividade humana em que há conexões emocionais, de amor, de altruismo e de engajamentos baseados em normas. Os especialistas em sociologia econômica falam muito de redes e de instituições, mas eles também evitam considerar qualquer engajamento e conexão emocionais" (England e Folbre, 2005, p. 643). Elas citam como exemplo as atividades de care:

O estudo emergente das atividades de care mostra que elas não satisfazem numerosas hipóteses standard e que desafiam numerosas dicotomias. Elas parecem produzir exterioridades e bens coletivos, 
e os próprios economistas admitem que estes fatores "varrem" suas hipóteses habituais sobre a eficácia dos mercados (England e Folbre, 2005, p. 643).

Os especialistas franceses chegam a conclusões no mesmo sentido. Isabelle Guérin mostrou como "a economia solidária" abre possibilidades para que os esforços das mulheres sejam compensados com equidade. Enfatizando a urgência em matéria de políticas adequadas de care, Florence Weber declara a este mesmo respeito:

Cessemos de crer automáticos os sentimentos e as obrigações ligados à paternidade. Lutemos pela profissionalização dos empregos no setor do care, para aproximar as condições de trabalho a domicílio daquelas das instituições, sem, por isso, suprimir o conforto para o dependente e seus familiares envolvidos no atendimento domiciliar. (Weber, 2005, p. 258)

Além disso, estas críticas assinalam que as hipóteses dos Mundos hostis, que consideram o amor e o care como degradados pela monetarização, podem, na realidade, fundamentar políticas injustas e serem a causa de discriminação econômica em relação a estas atividades do setor do care, tidas como intangíveis; por exemplo:

1. recusa em considerar que certos trabalhos domésticos devem ser remunerados

2. falta de segurança econômica para as atividades de care que não são pagas

3. salários pouco elevados para certos trabalhos de care, como o das babás ou das auxiliares de enfermagem a domicílio

4. recusa de assistência social a mães não casadas, sob pretexto que ela as incita à dependência

5. resistência à remuneração dos pais pelos trabalhos de care

Pensemos no doloroso impacto, sobre as mães de crianças doentes crônicas, da reforma americana da assistência social, de 1996, que introduziu rigorosas exigências de trabalho aos beneficiários. Segundo um estudo detalhado, estas mulheres se encontram frente a um terrível dilema: se elas trabalham, seus filhos doentes não têm mais os cuidados apropriados, mas se param de trabalhar para cuidar de seus filhos, perdem seus subsídios da ajuda social. Para aumentar as dificuldades, poucos estabelecimentos de atendimento americanos estão preparados para receber estas crianças. Uma dezena de organizações médicas relacionadas a essa questão propuseram uma solução: mudar a política de ajuda social para que o cuidado de crianças doentes seja considerado um trabalho, permitindo, assim, que as mães satisfaçam à 
exigência de trabalho. Mas a proposição foi recusada. Pelo contrário, o governo Bush pediu que as exigências de trabalho fossem aumentadas \{Chavkin, 2006; "Doctors Spesk Out", 2006].

Tendo o care pago se tornado social e moralmente legítimo, agora as feministas não defendem mais a necessidade da sua remuneração, daqui para adiante, elas procuram enfatizar o montante e a forma de pagamento, e o estudo das relações reais de care pago. O problema não está, dizem elas, no fato do dinheiro estar implicado e, sim, em identificar qual o sistema de pagamento que é utilizado na relação de care. Para que o care saia de seu gueto de marginalidade econômica, elas defendem vigorosamente sua fundamental significação econômica e seu conteúdo econômico variado.

Para além da concordância geral em torno do fato de que os trabalhos de care sejam atualmente mal remunerados e menos valorizados, devemos compreender que as formas e as próprias condições de pagamento são importantes. Um pagamento diário em dinheiro implica uma relação muito diferente do que a de um pagamento por cheque mensal. Atribuir importância à forma de pagamento não tem nada de trivial. Temos numerosas provas que atestam como a forma de compensação interessa, inclusive aos dirigentes de grandes empresas que, além da remuneração monetária, comumente recebem uma série de vantagens em espécie. Suprima o carro fornecido pela empresa, os banheiros reservados à direção ou as viagens de prestígio e você estará diminuindo parte daquilo que distingue um executivo dirigente de outros. Os mesmos princípios se aplicam à associação entre crianças, fornecedoras de care e sua compensação.

O estudo do care levanta, portanto, questões bem mais gerais a respeito da própria análise das relações íntimas nos processos econômicos. Não iremos muito longe enquanto a sombra dos Mundos hostis e do Comércio em toda parte assombrar a análise. As variantes "extensão" e "contexto" da sociologia econômica também não resolvem o problema. Como confirmam recentes trabalhos franceses, somente uma análise alternativa inteiramente social dos processos de intimidade e de economia nos levará até onde é preciso ir.

\section{Referências}

BERNARDO, L. La place des sentiments dans l'aide professionnelle de gré a gré. In: WEBER, F; GOJARD, S; GRAMAIN, A. (eds). Charges de famille. Paris: La Découverte, 2003. p. 362-389.

BOLTANSKI, L.; CHIAPELLO, E. Le nouvel esprit du capitalism. Paris: Gallimard, 1999.

BOURDIEU, P. Les estructures sociales de l'economie. Paris: Le Seuil, 2000. 
CAILLÉ, A. Don, intèrêt et désintêressement. Paris: La Découverte, 1994.

CALLON, M. Introduction: the embeddedness of economic markets in economics. In: CALLON, M.(Org.). The laws of the Markets Blackwell. Oxford, 1998. p. 2-57.

CHAVKIN, W. (2006) Mothers of III Children, letter, The New York Review of Books, n. 53, p. 76-77, 2006.

CONVET, B.; HELBRON, J. Genèse de la sociologie économique américaine. In: HEIBRON, J; LENOIR, R.; SAPIRO, G. (Orgs). Pour une histoire des sciences sociales: Hommage à Pierre Bourdieu. Paris: Fayard, 2004. p. 223-241.

CUSIN, F.; BENAMOUZIG, D. Economie et sociologie. Paris: PUF, 2004 (Coll. Quadrige).

Doctors speak out about welfare reform. Finding common ground. New York. Disponível em: <www.findingcommonground.hs.Columbiaedu/speakout.pdf $>$. Consultado em: 1 abr. 2008.

DUFY, C.; WEBER, F. L'ethnographie èconomique. Paris: La Découverte, 2007.

ENGLAND, P.; FOLBRE, N. Folbre. Gender and economic sociology. In: SMELSER, N.; SWEDBERG, R (Eds.). The handbook of economic sociology. 2. ed. Russell Sage Foundation e Princeton University Press, 2005. p. 627-649.

FOLBRE, Nancy; NELSON, Julie A. For Love or Money - or both? Journal of Economic Perspectives, American Economic Association, v. 14, n. 4, p. 123-140, 2000 .

GISLAIN J,-J.; STEINER, P. La sociologie economique 1890-1920. Paris: PUF, 1995.

GUÉRIN, I. Femmes et economie solidaire. Paris: La Découverte, 2003.

HASSOUN, J.-P. (Org.). Négoces dans la ville. Ethnologie française. Paris, n. 35, esp., 2005.

HONDAGNEU-SOTELO, P. Doméstica. Berkeley: University of California Press, 2001.

L'argent en famille, Terrain, n. 45, Paris: Maison des Sciences de l'Homme, 2005.

LA PRADELLE, M. de. Les vendredis de Capentras. Paris: Fayard, 1996.

LEBARON, F. La croyance économique: les economists entre science et politique. Paris: Le Seuil, 2000.

McLAUGHLIN, E.; KRAUS, N. The nanny diaries. New York: St. Martin's Press, 2002.

NELSON, J. A..One sphere or two? In: ZELIZER, V. A (Ed.) Changing forms of payment, American Behavioral Scientist, n. 41, esp., p. 1467-1471, 1998.

ORLÉAN, A. La sociologie économique et la question de l'unité des sciences sociales. In: STEINER, P.; THIS SAINT-JEAN, I. (Orgs.). Sociologies économiques. L'Année sociologique, Paris, n. 55, esp., p. 279-305, 2005.

SCIARDET, H. Les marchands de l'aube: ethnographie et théorie du commerce aux puces de Saint-Ouen. Paris: Economica, 2003. 
SERVET, J.-M.; GUÉRIN I. (Orgs.). Une économie sans argent: les systèmes d'échange local. Paris: Le Seuil, 1999.

SERVET, J.-M.; GUÉRIN, I (Orgs.). Exclusion et liens financiers. Paris: Economica, 2002.

STEINER, P. Gift of blood and organs: the market and "fictitious" commodities. Revue française de sociologie, Paris, v. 44, supl., p. 147-162, 2003.

STEINER, P. H.; THIS SAINT-JEAN, I. (Orgs.). Sociologies économiques. L'Année sociologique, n. 55, 2006.

STEINER, P. La sociologie économique. Paris: La Découverte, 1999.

THIS SAINT-JEAN, I. This Saint-Jean, I. (2005), Peut-on definir la sociologie économique? In: STEINER, P.; THIS SAINT-JEAN, I. (Orgs.). Sociologies économiques, L'Année sociologique, n. 55, esp., p. 307-326, 2005.

WACQUANT, L. Corps et âme. Marselha: Agone, 2002.

WEBER, F. Le sang, le nom, le quotidian: une sociologie de la parenté pratique. La Courneuve: Aux lieux d'être, 2005.

WEBER, F;.GOJARD, S.; GRAMAIN, A. Charges de famille. Paris: La Découverte, 2003. 